\title{
Residential choice from a multiple criteria sustainable perspective
}

\author{
V. Liern ${ }^{2} \cdot$ B. Pérez-Gladish ${ }^{1}$ (D) F. Rubiera-Morollón ${ }^{1} \cdot$ B. M'Zali $^{3}$
}

Accepted: 4 December 2021

(c) The Author(s) 2021

\begin{abstract}
Minimizing travel in the urban environment facilitates the development of sustainable cities. A key aspect is that there is a wide supply of amenities and facilities in the neighbourhoods: if most of the needs of families, goods and services can be covered from the sub-centers of the residential areas, it will be possible to reduce daily intra-urban mobility. The objective of this work is to propose a ranking multicriteria method that facilitates the choice of an ideal residential location in terms of neighbourhood characteristics, especially in the search of sustainable mobility for each family characteristics. One of the main problems in several Multiple Criteria Decision Making methods is the assignment of criteria weights in the aggregation process. The proposed methodology in this paper, Un-weighted TOPSIS (UW-TOPSIS) is able to overcome that problem. In this Multiple Criteria Decision Making (MCDM) method the relative proximity of each decision alternative to an ideal solution is minimized for the un-known weights of the criteria which are the variables in the corresponding mathematical programming program. Thus, a ranking based on the relative proximity of each alternative to an ideal alternative is obtained without the a priori establishment of the criteria weights. The use of subjective weights in real decision making contexts, where for instance a ranking of alternatives is required, is subject to important criticisms. This could be the case of the ranking of neighbourhoods based on their sustainability.
\end{abstract}

Keywords MCDM · TOPSIS · Ranking · Neighbourhood sustainability

\section{Introduction}

Minimizing travel in the urban environment facilitates the development of sustainable cities. A key aspect is that there is a wide supply of amenities and facilities in the neighbourhoods (Choguill, 2008). If most of the needs of families, goods and services -public and private-, can

\footnotetext{
B. Pérez-Gladish bperez@uniovi.es

1 University of Oviedo, Oviedo, Spain

2 University of Valencia, Valencia, Spain

3 University of Quebec in Montreal, UQAM, Montreal, Canada
} 
be covered from the sub-centers of the residential areas, it will be possible to reduce daily intraurban mobility. This neighbourhood offer must be complemented with good accessibility to the main center or to other spaces in the city supported by efficient infrastructures or public transport services (Sharifi, 2016).

This idea was already present in the classic models of urban geography. The combination of the classic works of Von Thünen (1826) and Christaller (1935) allows us to conclude that an ideal city model is one that combines a main center with a network of hierarchical sub-centers (Breheny, 1996). Already in the second half of the twentieth century, the AMM model, developed by Alonso (1964), Muth (1969) and Mills (1987), focuses its attention on understanding how the main center structures the location of activities throughout the city, paying less attention to the role of sub-centers of residential areas. For a long time, this will be the main focus of models of geography and urban economics, but with the recent rise of the literature on urban sustainability, the importance of the role of neighbourhoods and sub-centers in the confirmation of sustainable cities has resurfaced (Glaeser \& Kahn, 2001).

Neighbourhood sustainability is defined in Yigitcanlar et al. (2015) as 'the process of developing a neighbourhood level urban form or built environment that meets the needs of its residents whilst avoiding unacceptable social and environmental impacts both locally and in a broader context'. One of the key aspects of sustainability at the neighborhood scale is accessibility to local amenities as well as to frequent destinations. All these advantages make sustainable neighbourhoods attractive residence options as they increase residents' happiness and their quality of life (see Alshuwaikhat \& Aina, 2006; Cloutier et al., 2014 and Song \& Quercia, 2008).

Assuming that residential location decisions involve many different dimensions and decision criteria that interact with each other, the objective of this work is to propose a decision framework that facilitates the choice of ideal residential location in terms of neighbourhood characteristics, especially in terms of sustainability, for different residents' profiles.

Ortega-Momtequín et al. (2021) proposed the combined use of two well-known Multiple Criteria Decision Making (MCDM) methods, TOPSIS and AHP, for the ranking of different neighborhoods within a city based on sustainability criteria and for different family profiles. TOPSIS (Technique for Order Preference by Similarity to Ideal Solution) proposed by Hwang and Yoon (1981) is a ranking method based on the idea of relative proximity to an ideal solution. The method simultaneously minimizes the distance of each alternative to a positive ideal solution (PIS) and maximizes distance to a negative ideal solution (NIS). The positive ideal solution includes the best value of each criterion and the negative ideal solution is composed of the worst values of the decision criteria. Several works can be found in the literature were TOPSIS is applied in combination with other MCDM methods to assess and rank different decision alternatives integrating different indicators. Ture et al. (2019), Fu et al. (2020), Rafiaani et al. (2020), Parada et al. (2019) or Pawlewicz et al. (2020) are just some recently published examples.

The Analytic Hierarchy Process (AHP) proposed by Saaty (1980) and particularly the eigenvalue method (EM), is one of the most popular methods for the derivation of priorities in decision problems with hierarchic structures consisting of a goal, decision criteria and alternatives. In each hierarchical level, the decision maker offers subjective judgements based on his/her expertise level making paired comparisons using a numerical scale. OrtegaMomtequín et al. (2021) used the eigenvalue method to obtain subjective weights reflecting the relative importance of the decision criteria. Those subjective weights were incorporated into the TOPSIS procedure in order to aggregate the different decision criteria for each family profile. 
Determining weights, particularly subjective ones, is one of the most controversial issues in many multi-criteria decision-making methodologies. The Sustainable Cities Index is one example. This index measures the progress of cities towards the compliance of the Sustainable Development Goals approved by United Nations in 2015. This index represents a pioneering effort at the international level being one of the first to take sub-national regions as a unit of analysis, taking as a reference the goals of the 2030 Agenda. The Sustainable Cities Index uses the same methodology than the Sustainable Development Goals (SDG) Index. In the methodology section of the last report the authors state with regards to the weighting and aggregation processes in the construction of the index:

Several rounds of expert consultations on earlier drafts of the SDG Index made it clear that there was no consensus across different epistemic communities on assigning higher weights to some SDGs over others. As a normative assumption, we therefore opted to give fixed, equal weight to every SDG, reflecting the commitment of policymakers to treat all SDGs equally as part of an integrated and indivisible set of goal (Sachs et al., 2021).

With the methodology proposed in this article, UW-TOPSIS, we try to solve this problem. The method does not require the a priori establishment of subjective weights. On the contrary, the weights are decision variables in an optimization problem where the objective is to determine the best solution for each decision alternative understood the latter as the best possible relative proximity of the alternative to the ideal solution of the model.

The ranking of alternatives based on UW-TOPSIS method is, therefore, more robust. The method also allows us to easily identify the weaknesses and strengths of each decision alternative with respect to the decision criteria, in our case of each neighborhood, therefore offering opportunities for improvement to these locations.

The rest of the work is organized as follows: in the next section we describe the proposed method, UW-TOPSIS. In Sect. 3, we present the sustainable housing location decision problem from a multi-criteria perspective and apply the proposed methodology to the ranking of neighborhoods in the city of Oviedo. The work ends with the discussion of results and conclusions.

\section{Un-weighted TOPSIS (UW-TOPSIS)}

TOPSIS is a widely used MCDM simply method with nice properties that provides a cardinal ranking of alternatives, allowing total linear compensation using a single criterion aggregation approach (Chen and Hwang, 1992; Yoon and Hwang, 1995; Roy, 1996 and Behzadian et al., 2012). The relative importance of the decision criteria, given by the criteria weights, are usually given objectively or subjectively, by the decision makers in the first steps of the algorithm (Watröbski et al., 2019; Ouenniche et al., 2018). Although the use of subjective weighting schemes is common in Multiple Criteria Decision Analysis models, subjective weighting schemes are more controversial than objective ones as they could determine the position in a ranking or, in general, they could determine any decision making (see Barron and Barret, 1996; Hobbs, 1980; Alemi-Ardakani et al., 2016; Eshlaghy and Radfar, 2006; Németh et al., 2019 and Deng et al., 2000). Subjective weights, usually directly established by the decision maker based on expert knowledge or subjective preferences, are difficult to be uphold. The obtained rankings are usually very sensitive to changes on the weights.

In what follows we will present the steps of the new algorithm proposed by Liern and Pérez-Gladish $(2020,2021)$ which does not require the introduction of a priori weights. 
Steps 1 and 2 remain the same than in TOPSIS. However, the PIS and NIS solutions are determined now without taking into account the relative importance of the criteria. Weights are introduced as unknowns in step 4 when separation measures from the PIS and NIS are calculated. Their values are determined in step 5 solving two groups of mathematical programing problems which maximize and minimize the separation of each alternative to the PIS and NIS respectively, taking into account different constraints referred to the values of the weights. These constraints include the classical constraint in TOPSIS approaches which ensures all the weights are positive and sum up one and other constraints imposing lower and upper bounds on the weights. The resulting mathematical programming problems are, due to the nature of their objective, fractional mathematical programming problems. In what follows we describe the main steps of the method in detail.

Step1 Determine the decision matrix $\left[x_{i j}\right], 1 \leq i \leq n, 1 \leq j \leq m$, where the number of alternatives is $n$ and the number of criteria is $m$.

Step 2 Construct the normalized decision matrix

$$
\left[r_{i j}\right], r_{i j} \in[0,1], 1 \leq i \leq n, 1 \leq j \leq m .
$$

Step 3 Determine the positive ideal $A^{+}=\left(r_{1}^{+}, \ldots, r_{m}^{+}\right)$and the negative ideal solutions. $A^{-}=\left(r_{1}^{-}, \ldots, r_{m}^{-}\right)$, where

$$
\begin{aligned}
& r_{j}^{+}=\left\{\begin{array}{l}
\max _{1 \leq i \leq n} r_{i j}, j \in J \\
\min _{1 \leq i \leq n} r_{i j}, j \in J^{\prime}
\end{array} \quad 1 \leq j \leq m,\right. \\
& r_{j}^{-}=\left\{\begin{array}{l}
\min _{1 \leq i \leq n} r_{i j}, j \in J \\
\max _{1 \leq i \leq n} r_{i j}, j \in J^{\prime}
\end{array} \quad 1 \leq j \leq m,\right.
\end{aligned}
$$

where $J$ is associated with "the more, the better" criteria and $J$ ' is associated with "the less, the better" criteria.

Step 4 Let us consider $\Omega=\left\{w=\left(w_{1}, \ldots, w_{m}\right) \in \mathbb{R}^{m}, w_{j} \in[0,1], \sum_{j=1}^{m} w_{j}=1\right\}$. Given $A^{+}, A^{-}$, we define two separation functions, Given by

$$
\begin{gathered}
D_{i}^{+}: \Omega \times \mathbb{R}^{m} \rightarrow[0,1], D_{i}^{-}: \Omega \times \mathbb{R}^{m} \rightarrow[0,1], \quad 1 \leq i \leq n, \\
D_{i}^{+}(w)=d\left(\left(w_{1} r_{i 1}, \ldots, w_{m} r_{i m}\right),\left(w_{1} r_{1}^{+}, \ldots, w_{m} r_{m}^{+}\right)\right), 1 \leq i \leq n, \\
D_{i}^{-}(w)=d\left(\left(w_{1} r_{i 1}, \ldots, w_{m} r_{i m}\right),\left(w_{1} r_{1}^{-}, \ldots, w_{m} r_{m}^{-}\right)\right), 1 \leq i \leq n,
\end{gathered}
$$

where $d$ is a distance function in $\mathbb{R}^{m}$.

Step 5 Calculate the function of relative proximity to the ideal solution, $R_{i}: \Omega \rightarrow$ $[0,1], \quad 1 \leq i \leq n$, as

$$
R_{i}(w)=\frac{D_{i}^{-}(w)}{D_{i}^{+}(w)+D_{i}^{-}(w)}, \quad 1 \leq i \leq n
$$

Step 6 For each $i, 1 \leq i \leq n$, we calculate the values $R_{i}^{\min }(w), R_{i}^{\max }(w)$ solving the two following mathematical programming problems where decision variables are the criteria 
weights:

$$
\begin{aligned}
& R_{i}^{\text {min }}=\operatorname{Min}\left\{R_{i}(w), \sum_{j=1}^{m} w_{j}=1, l_{j} \leq w_{j} \leq u_{j}, 1 \leq j \leq m\right\}, \quad 1 \leq i \leq n, \\
& R_{i}^{\text {max }}=\operatorname{Max}\left\{R_{i}(w), \sum_{j=1}^{m} w_{j}=1, l_{j} \leq w_{j} \leq u_{j}, 1 \leq j \leq m\right\}, \quad 1 \leq i \leq n,
\end{aligned}
$$

being $l_{j}, u_{j} \geq 0$ lower and upper bounds for each criterion's weight. Then, we obtain $n$ relative proximity intervals,

$$
R_{i}^{I}=\left[R_{i}^{\min }, R_{i}^{\max }\right], \quad 1 \leq i \leq n
$$

Step 7 We rank the intervals $R_{1}^{I}, R_{2}^{I}, \ldots, R_{n}^{I}$.

According to Canós and Liern (2008), given the intervals $A=\left[a_{1}, a_{2}\right]$, and $B=\left[b_{1}, b_{2}\right]$ contained in $\mathbb{R}$, we will say that $A$ is bigger than $B$, if and only if

$$
A \succ B \Leftrightarrow\left\{\begin{array}{l}
k_{1} a_{1}+k_{2} a_{2}>k_{1} b_{1}+k_{2} b_{2}, \quad k_{1} a_{1}+k_{2} a_{2} \neq k_{1} b_{1}+k_{2} b_{2} \\
a_{1}>b_{1}, \quad k_{1} a_{1}+k_{2} a_{2}=k_{1} b_{1}+k_{2} b_{2}
\end{array}\right.
$$

where $k_{1}$ and $k_{2}$ are two pre-established positive constants. In the context that concerns us, the values $k_{1}$ and $k_{2}$ inform us about the degree of confidence of the decision maker that the alternatives are in their best position or on the contrary (Canós and Liern, 2008). When ordering the intervals $\left[R_{i}^{\min }, R_{i}^{\max }\right], 1 \leq i \leq n$, the relation $k_{2} / k_{1}$ informs us about the importance (or truthfulness) given to the best situation of the alternatives $R_{i}^{\max }$ regarding of the worst situation $R_{i}^{\min }$. In the next section, since we do not have information that makes us opt for the best or worst situation, we have chosen to give the same importance to both, that is, $k_{1}=k_{2}=1$.

Let us notice that, by construction, UW-TOPSIS is a generalization of the TOPSIS approach (see Table 1). Indeed, if some conditions are added to the formulation of the UW-TOPSIS, the latter coincides with the TOPSIS approach.

Consideration of $A^{+}=(1, \ldots, 1)$ and $A^{-}=(0, \ldots, 0)$ is not as restrictive as it may seem. In fact, it would be enough to transform all the criteria into the-more-the better criteria (Ouenniche et al., 2018) and to consider the PIS and NIS as ideal values independent from the data, such that they do not need to be modified if new data are incorporated. On the other hand, if we normalize data taking into account their similarity with the ideal reference,

$$
\overline{r_{i j}}=\left\{\begin{array}{cl}
\frac{x_{i j}-A_{j}}{a_{j}-A_{j}}, & A_{j} \leq x_{i j}<a_{j} \\
1, & a_{j} \leq x_{i j} \leq b_{j} \quad 1 \leq i \leq n, 1 \leq j \leq m \\
\frac{B_{j}-x_{i j}}{B_{j}-b_{j}} & b_{j}<x_{i j} \leq B_{j}
\end{array}\right.
$$

where $\left[A_{j}, B_{j}\right]$ is the range for the valuations of criterion $j$ and $\left[a_{j}, b_{j}\right] \subseteq\left[A_{j}, B_{j}\right]$ is the ideal fixed for criterion $j$, then it can be easily demonstrated that $\mathrm{A}^{+}$and $\mathrm{A}^{-}$will be $A^{+}=$ $(1, \ldots, 1), A^{-}=(0, \ldots, 0)$ (see Acuña-Soto et al. 2018). 


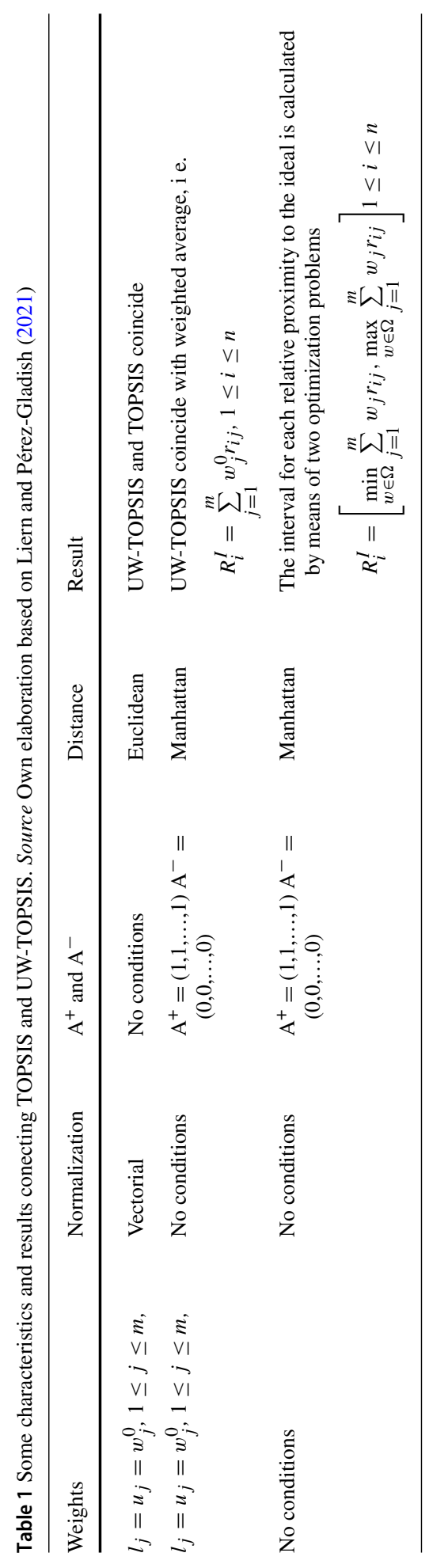




\section{Multiple criteria residential choice problem from a sustainable perspective}

Let us consider the residential choice problem proposed by Ortega-Momtequín et al. (2021). The city of Oviedo is located in northern Spain with a total population of 220,448 inhabitants and a total of 125,495 homes (data from the City Council, 2019). The city is the capital of Asturias (NUTS-2 region) and is a good example of a compact European city part of a complex metropolitan area.

Following Ortega-Momtequín et al. (2021) we will consider as neighbourhoods 164 census districts of the municipality of Oviedo provided by the National Institute of Statistics and 8 decision criteria organized into three different dimensions, social, environmental and economic. Tables 2 and 3 describe, respectively, decision criteria by dimension and selected indicators.

Table 2 Main sustainability dimensions and criteria Source Ortega-Momtequín et al. (2021)

\begin{tabular}{ll}
\hline Dimension & Description of criteria \\
\hline Social & C1 Distance to the nearest health centre \\
& These distances are measured according to the time a pedestrian takes to get from \\
& the geometric centre of a district to the health centre (average speed of $4 \mathrm{~km} / \mathrm{h}$ ). For \\
& this purpose, the GIS raster tool Cost Distance was applied to a mapped pedestrian \\
& space (source, urban planning), which calculates the distance of the lowest \\
& accumulated cost (time) on a grid of pixels of one metre
\end{tabular}

C2 Number of primary schools in education area

This is a count of the number of primary schools that exist in each educational area; the educational areas do not always coincide with the census districts and thus each district is given the value that corresponds to most of its surface

Environmental C3 Distance to the city centre

The described pedestrian access time technique (see criterion C1) is used, this time for distance to a symbolic centre of the city (crosswalk between San Francisco Park and the Plaza de la Escandalera)

\section{C4 Building density}

Divides the constructed area (according to cadastral data) by the surface of the district, resulting in $\mathrm{m}^{2}$ built $/ \mathrm{m}^{2}$ land. As a reference, values lower than $1 \mathrm{~m}^{2} / \mathrm{m}^{2}$ can be considered low-density spaces and higher ones as high-density spaces

\section{C5 Distance to a green park}

The described pedestrian access time technique (see criterion $\mathrm{C} 1$ ) is used, this time for distance to parks larger than $10,000 \mathrm{~m}^{2}$

C6 Distance to a train or bus station

The described pedestrian access time technique (see criterion $\mathrm{C} 1$ ) is used, this time for the distance to the bus station and the three existing train stations

C7 Distance to a highway link

In this criterion the distance is measured by the time it takes to drive from the centre of a district to a highway link. The GIS technique is a network analyst, in which speeds $(20,40$ and $110 \mathrm{~km} / \mathrm{h})$ and the circulation directions are simplified (source of the network: National Geographic Institute)

Economic

C8 Dwelling average price

The average price per square metre of each district from a sample of 3,728 listings of dwellings for sale in October 2018 
Table 3 Type of decision criteria and individual indicators. Source Ortega-Momtequín et al. (2021)

\begin{tabular}{llll}
\hline Criterion/Indicator & Description & Type & \\
\hline C1 & DHEALTH & Distance to the nearest health centre & Minimize \\
C2 & SCHOOL & Number of primary schools in education area & Maximize \\
C3 & DCENTER & Distance to the city centre & Minimize \\
C4 & BDENSITY & Building density & Minimize \\
C5 & DGREEN & Distance to a green park & Minimize \\
C6 & DTRANS & Distance to a train or bus station & Minimize \\
C7 & DMOTOR & Distance to a highway link & Minimize \\
C8 & PRIZE & Dwelling average price & Minimize \\
\hline
\end{tabular}

In Ortega-Momtequín et al. (2021) several decision maker profiles were considered and the relative importance of the decision criteria for each different decision maker's profile, criteria weights were obtained from an expert using the Analytical Hierarchy Method, AHP. A ranking of the neighbourhoods based on each family profile was obtained taking into account the subjective preferences obtained using AHP.

In what follows, we will illustrate how UW-TOPSIS allows us to rank the same neighbourhoods based on the same decision criteria without a priory information from the decision maker or experts relative to their subjective criteria preferences. With illustrative purposes, we will use the family profile 1, P1: Young couple or singles without children, considered in Ortega-Momtequín et al. (2021).

Table 4 displays the decision criteria weights obtained from the expert using AHP. As we can observe, based on the pairwise comparisons provided by the expert, this kind of family gives the most importance to the dwelling average price, closely followed by the distance to the city centre (see Table 4). The number of primary schools in education area, on the other hand, is given by far the less importance.

Table 5, in the appendix, shows the obtained ranking using TOPSIS and AHP for the obtaining of the criteria weights. Table 5 also displays the ranking obtained using UWTOPSIS which does not require a priori determination of weights. First column shows the alternatives (our neighbourhoods). Second column displays the relative proximity using TOPSIS and subjective weights (see Table 4). Columns four, five and six display the relative proximity intervals (lower and upper extremes) and average relative proximity values using UW-TOPSIS.

It is easy to observe how the obtained rankings using both, TOPSIS with AHP and UWTOPSIS are quite similar. However, there are few differences. Neighbourhood 115 ranks better with AHP-TOPSIS and neighbourhood 107 occupies a better position with UWTOPSIS. However, the position of this alternative is quite stable regardless the criteria weights

Table 4 Criteria weights by profile obtained with AHP. Source Ortega-Momtequín et al. (2021)

\begin{tabular}{lllllllll}
\hline & C1 & C2 & C3 & C4 & C5 & C6 & C7 & C8 \\
\hline Profile 1 & 0.052 & 0.026 & 0.291 & 0.077 & 0.043 & 0.103 & 0.113 & 0.296 \\
\hline
\end{tabular}


and this could indicate that the ranking obtained applying TOPSIS with AHP might not be fully recognizing the good features of this alternative.

Figure 1 shows the obtained ranges of variation of the relative proximity minimum, maximum and average values for each decision alternative or neighbourhood. It is interesting to observe how most of the ranges of variation of the relative proximity intervals remain in the same zone of the graphic. However, the are several neighbourhoods with relative proximity intervals ranging in a different zone, showing worse (smaller) relative proximity values. For these alternatives, regardless the relative importance given to the decision criteria, the position of the neighbourhood in the ranking would be clearly below the $50 \%$ of better positioned alternatives. This is the case of alternatives or neighbourhoods 43, 69, 78, 74 and 121. Let us observe how, even in the best possible scenario (maximum relative proximity value), these neighborhoods would be ranked in the lower positions.

This gives us an idea of the practical applicability of UW-TOPSIS in real decision situations in which the establishment of subjective weights could alter too much the position in the ranking of the alternative, in some occasions, with important political and/or economic consequences.

Another interesting information derived from the application of this method is that related to the amplitude of the relative proximity intervals (see Table 5). If the interval of variation

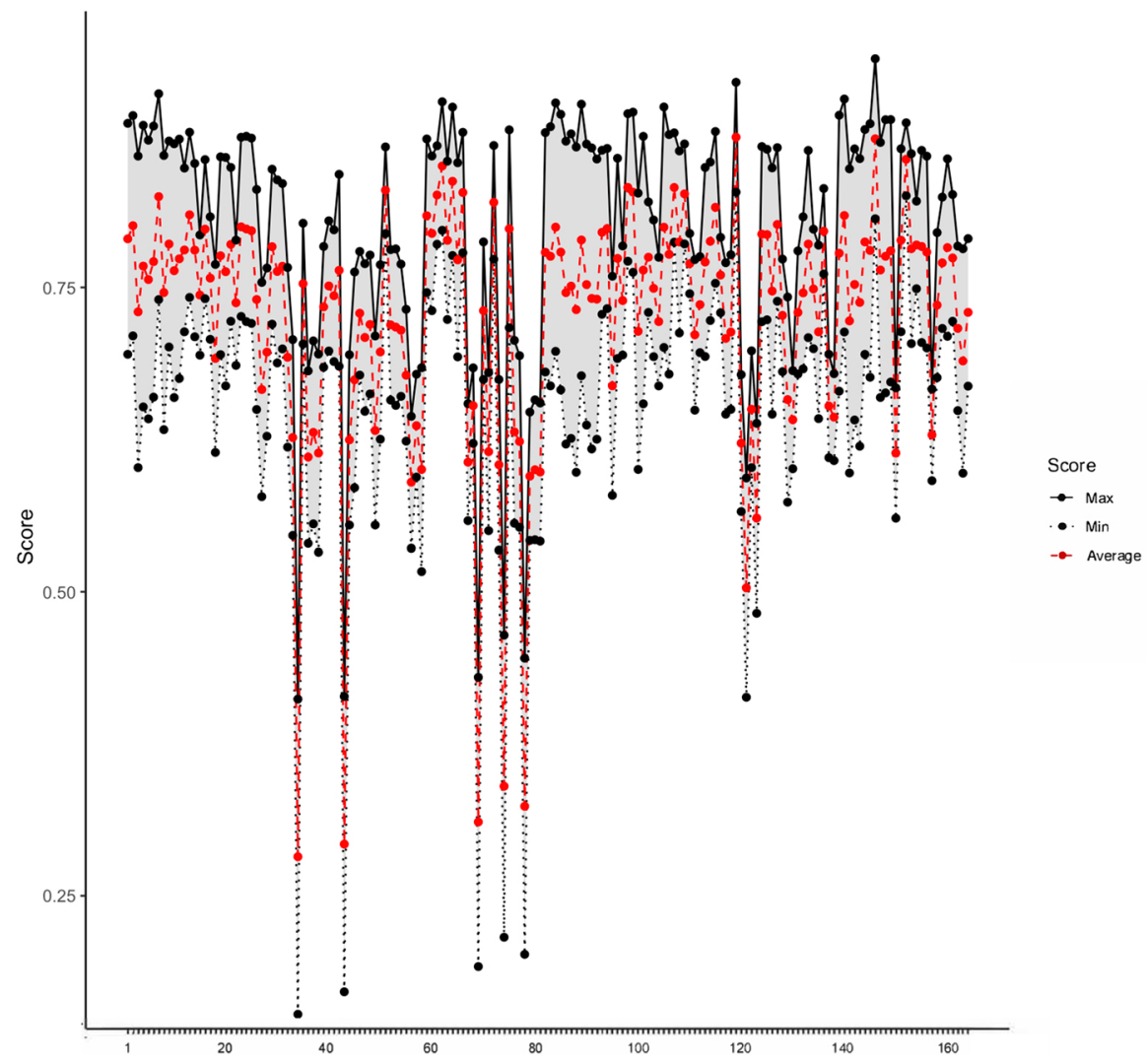

Fig. 1 Individual ranges of variations of UW-TOPSIS relative proximity values 
of the relative proximity of the alternative is not very wide, this means the position of the alternative in the ranking is quite stable and, in general, the establishment of the criteria weights is not a key question in determining the position of the neighbourhood in the ranking. In Table 5 we can see how alternatives ranked in the first positions with UW-TOPSIS have all very small interval amplitudes, meaning this that the position of the neighbourhoods in the ranking is quite stable and does not depend on the relative importance of the decision criteria. Alternative 34, on the other hand, has a relative proximity interval with a wide range of variation. Depending on the criteria weights this neighbourhood can occupy quite different positions in the ranking.

\section{Conclusions}

In a previous work, Ortega-Momtequín et al. (2021) proposed a Multiple Criteria Decision Making model based on two well-known methods, TOPSIS and AHP, to aid families in their location decisions in terms of neighbourhoods taking into account sustainability criteria. In that work, neighbourhoods in a city were ranked for different family profiles taking into account six decision criteria, using TOPSIS. The AHP technique was integrated into the TOPSIS algorithm in order to provide subjective weights for the decision criteria and for each family profile. Several rankings were obtained for each decision maker profile. Although highly flexible and easy to implement, the obtained results were highly subjective as they mostly depend on the subjective weights established by different particular decision makers.

In this work, we try to show how UW-TOPSIS is able to overcome the above-described limitation, being able to provide flexible rankings not dependent on the criteria weights. A relative proximity interval can be obtained for each alternative (neighbourhood) which allows the knowledge of the position of each alternative in the raking taking into account different scenarios ranging from the worst to the best. This information could be of particular utility for those decision makers not willing or not able to fix a priori exact weights showing the relative importance of the decision criteria.

The proposed procedure can be a very valuable tool for real estate agents, construction companies or urban planners. All of them can make different uses of the tool either to provide a service better adapted to the client or, in the case of urban planners and managers, to make projections, evaluate alternatives or evaluate ex-ante policies. In the academic field, it is very interesting to apply the procedure to different urban realities so that it is possible to compare how identical profiles may have different preferences depending on the features of a city. For example, in the case of Oviedo, a city with very low birth rates and a high ageing population, a reduction in large families is foreseen in favour of older couples. The neighborhood most desired by the profile of older couples will present greater pressure in the coming years. But in other realities it may be that the profile that is experiencing the greatest growth is that of young middle-class families, as occurs in many Latin American cities, or professionals without children, more frequent in cities specialized in the financial sector or consulting activities. This type of exercise makes the combination of the proposed procedure with demographic projections expand its potential.

Funding Open Access funding provided thanks to the CRUE-CSIC agreement with Springer Nature. This work has been supported by the Spanish Ministerio de Ciencia, Innovación y Universidades, project number: RTI2018-093541-B-I00. 
Open Access This article is licensed under a Creative Commons Attribution 4.0 International License, which permits use, sharing, adaptation, distribution and reproduction in any medium or format, as long as you give appropriate credit to the original author(s) and the source, provide a link to the Creative Commons licence, and indicate if changes were made. The images or other third party material in this article are included in the article's Creative Commons licence, unless indicated otherwise in a credit line to the material. If material is not included in the article's Creative Commons licence and your intended use is not permitted by statutory regulation or exceeds the permitted use, you will need to obtain permission directly from the copyright holder. To view a copy of this licence, visit http://creativecommons.org/licenses/by/4.0/.

\section{Appendix}

See Table 5 .

\section{References}

Acuña-Soto, C., Liern, V., \& Pérez-Gladish, B. (2018). Normalization in TOPSIS-based approaches with data of different nature: Application to the ranking of mathematical videos. Annals of Operations Research. https://doi.org/10.1007/s10479-018-2945-5.

Alemi-Ardakani, M., Milani, A. S., Yannacopoulos, S., \& Shokouhi, G. (2016) On the effect of subjective, objective and combinative weighting in multiple criteria decision making: A case study on impact optimization of composites. Expert Applications, 46, 426-438.

Alonso, W. (1964). Location and land use: Toward a general theory of land rent. Harvard University Press.

Alshuwaikhat, H., \& Aina, Y. (2006). GIS-based urban sustainability assessment: The case of Dammam city, Saudi Arabia. Local Environment, 11(2), 141-162.

Barron, F. H., \& Barrett, B. E. (1996). Decision quality using ranking attribute weights. Management Science, $42,1515-1525$.

Behzadian, M., Otaghsara, S. K., Yazdani, M., \& Ignatius, J. (2012). A state-of the-art survey of TOPSIS applications. Expert Systems with Applications, 39(7), 13051-13069.

Breheny, M. (1996). Centrist, decentriscts and compromisers: views on the future of urban form, in Jenks, M., Burton, E. \& Willians, K. (Eds.): The compact city: a sustainable urban form? E\&FN Spon.

Canós, L., \& Liern, V. (2008). Soft computing-based aggregation methods for human resource management. European Journal of Operational Research, 189, 669-681.

Chen, S. J., \& Hwang, C. L. (1992). Fuzzy multiple attribute decision making methods and applications, 375. Springer, Berlin.

Choguill, C. L. (2008). Developing sustainable neighbourhoods. Habitat International, 32(1), 41-48.

Christaller, W. (1935). Die Zentralen Orte in Süddeutschland. Fischer.

Cloutier, S., Larson, L., \& Jambeck, J. (2014). Are sustainable cities "happy" cities? Associations between sustainable development and sustainable development and human wellbeing in urban areas of the United States. Environ Dev. Sustainability, 16(3), 633-647.

Deng, H., Yeh, C. H., \& Willis, R. J. (2000). Inter-company comparison using modified TOPSIS with objective weights. Computers \& Operations Research, 27, 963-973.

Eshlaghy, A. T., \& Radfar, R. (2006). A new approach for classification of weighting methods. Management of Innovation and Technology, 2, 1090-1093.

Fu, Y., Xiangtianrui, K., \& Luo, H. (2020). Constructing composite indicators with collective choice and interval-valued TOPSIS: The case of value measure. Social Indicators Research, 152, 117-135. https:// doi.org/10.1007/s11205-020-02422-8

Glaeser, E. \& Kahn, M. (2001). Decentralized employment and the transformation of the American city, Brookings-Wharton papers on Urban Affairs, 1-47.

Hobbs, B. F. (1980). A comparison of weighting methods in power plant sitting. Decision Science, 11, 725-737.

Hwang, C. L., \& Yoon, K. (1981). Multiple attribute decision making methods and applications a State of the Art Survey. Springer.

Liern, V., \& Pérez-Gladish, B. (2020). Multiple criteria ranking method based on functional proximity index: Un-weighted TOPSIS. Annals of Operations Research. https://doi.org/10.1007/s10479-020-03718-1

Liern, V., \& Pérez-Gladish, B. (2021). Building composite indicators with unweighted-TOPSIS. IEEE Transactions on Engineering Management. https://doi.org/10.1109/TEM.2021.3090155 
Mills, E. S. (1987). Handbook of regional and urban economics, Vol. 2: Urban Economics. Amsterdam, North Holland.

Muth, R. F. (1969). Cities and housing. University of Chicago Press, Chicago.

Németh, B., Molnár, A., Bozóki, S., Wijaya, K., Inotai, A., Campbell, J. D., \& Kaló, Z. (2019). Comparison of weighting methods used in multicriteria decision analysis frameworks in healthcare with focus on lowand middle-income countries. Journal of Comparative Effectiveness Research, 8(4),195-204.

Ortega-Momtequín, M., Rubiera-Morollón, F., \& Pérez-Gladish, B. (2021). Ranking residential locations based on neighbourhood sustainability and family profile. International Journal of Sustainable Development \& World Ecology, 28(1), 49-63.

Ouenniche, J., Pérez-Gladish, B., \& Bouslah K. (2018). An out-of-sample framework for TOPSIS-based classifiers with application in bankruptcy prediction. TechnologicalForecasting and Social Change, 131, 111-116.

Parada, S. E., Blasco-Blasco, O., \& Liern, V. (2019). Adequacy indicators based on pre-established goals: An implementation in a Colombian University. Social Indicators Research, 143, 1-24. https://doi.org/10. 1007/s11205-018-1979-z

Pawlewicz, K., Senetra, A., \& Gwiaździńska-Goraj, M. (2020). Differences in the environmental, social and economic development of polish-Lithuanian trans-border regions. Social Indicators Research, 147, 1015-1038. https://doi.org/10.1007/s11205-019-02179-9

Rafiaani, P., Dikopoulou, Z., \& Van Dael, M. (2020). Identifying social indicators for sustainability assessment of CCU technologies: A modified multi-criteria decision making. Social Indicators Research, 147, 15-44. https://doi.org/10.1007/s11205-019-02154-4

Roy, B. (1996). Multicriteria methodology for decision aiding. Springer, Boston, M.A

Saaty, T. L. (1980). The analytic hierarchy process. McGraw-Hill.

Sachs, J. D., Kroll, C., Lafortune, G., Fuller, G., \& Woelm, F. (2021). Sustainable development report 2021. Cambridge University Press.

Sharifi, A. (2016). From Garden City to Eco-urbanism: The quest for sustainable neighborhood development. Sustainable Cities and Society, 20, 1-16.

Song, Y., \& Quercia, R. (2008). How are neighbourhood design features valued across different neighbourhood types? J. Hous Built Environ., 23(4), 297-316.

Ture, H., Dogan, S., \& Kocak, D. (2019). Assessing Euro 2020 strategy using multi-criteria decision making methods: VIKOR and TOPSIS. Social Indicators Research, 142, 645-665. https://doi.org/10.1007/ s11205-018-1938-8

Von Thünen J.H. (1826). Der Isolierte Staat in Beziehung auf Landwirtchaft und Nationalökonomie. Hambourg.

Watröbski, K., Jankiwski, J., Ziemba, P., \& Karczmarczyk, A. (2019). Generalised framework for multi-criteria method selection. Omega, 86, 107-124.

Yigitcanlar, T., Kamruzzaman, M. D., \& Teriman, S. (2015). Neighborhood sustainability assessment: Evaluating residential development sustainability in a developing country context. Sustainability, 7(3), 2570-2602.

Yoon, K. P., \& Hwang, C. L. (1995). Multiple attribute decision making an introduction. Sage publications, London, New Delhi.

Publisher's Note Springer Nature remains neutral with regard to jurisdictional claims in published maps and institutional affiliations. 